\title{
Why Right Mindfulness Might Not Be Right for Mindfulness
}

\author{
Jared R. Lindahl
}

Published online: 28 December 2014

(C) Springer Science+Business Media New York 2014

\section{Introduction}

Monteiro, Musten and Compson (2015) examined a number of critical issues in the ongoing debates concerning the nature of "mindfulness" and its applications within and beyond clinical psychology. Often appearing to take a neutral stance in relation to the debates between "traditional mindfulness" and "contemporary mindfulness," their primary aim was to "assess the validity" of criticisms concerning the conceptual integrity of contemporary mindfulness (p. 1). In particular, they evaluated the relationship of contemporary mindfulness to the Buddhist doctrines of "right mindfulness," the degree to which "suffering" is alleviated in traditional and contemporary mindfulness, and whether Buddhist ethics should play a more explicit and pronounced role in mindfulness-based interventions (MBIs). The authors were careful throughout the article to suggest what could be done rather than what should be done in the ongoing dialogue between traditional and contemporary mindfulness. This commentary suggests that this stance leaves a number of implicit assumptions unexamined or underexamined. In particular, two key issues will be explored: (1) the assumption that Buddhist conceptions of suffering and psychological conceptions of suffering are compatible and serve as an adequate point of departure for the translation of mindfulness from traditional contexts to contemporary applications in psychology and (2) the consequences of importing Buddhist ethical and normative frameworks associated with "right mindfulness" into contemporary mindfulness.

J. R. Lindahl $(\bowtie)$

Cogut Center for the Humanities, and Department of Religious Studies, Brown University, 59 George St., Box 1927, Providence, RI 02912, USA

e-mail: jared_lindahl@brown.edu

\section{Establishing Common Ground Between Buddhism and Psychology: the Problem of "Suffering"}

The field of contemporary mindfulness has developed under the assumption that Buddhist theories and practices have a contribution to make to clinical psychology, and indeed empirical research has demonstrated that for certain physiological and psychological problems, MBIs have a degree of efficacy that warrants their consideration as viable courses of treatment (Goyal et al. 2014). References to Buddhist theories and practices portraying them as philosophical, psychological, scientific, or even secular in nature have become commonplace among psychologists (Germer 2013; Miller 2014) and modern Buddhists alike (McMahan 2008). Wilson (2014) argued that the popular appeal of mindfulness is in part due to a process of "mystifying mindfulness" by removing or deliberately obscuring its connections to Buddhism, religion, and ethics. As Monteiro et al. (2015) illustrated, one fundamental assumption of MBIs is that traditional and contemporary forms of mindfulness "share a functional intent (to alleviate suffering)" (p. 1). While much has already been written on the challenges of defining and operationalizing "mindfulness" for clinical psychology and empirical research (Bishop et al. 2004; Bodhi 2011; Gethin 2011; Shaprio et al. 2006), less attention has been placed on exploring the additional challenges that arise when traditional Buddhist and contemporary psychological understandings of "suffering" are subjected to a careful investigation.

The central problem in establishing the compatibility of Buddhist and psychological notions of suffering is that there is no standard, operationalized definition of suffering used in clinical psychology. Rather, the tendency is to focus on components of suffering (e.g., stress, anxiety, and pain) rather than on suffering as such (Miller 2005), and different psychotherapies propose different models for the origin of these components of suffering and for their treatment. Cross-cultural 
differences in conceptions of suffering and coping strategies have been identified as additional obstacles in operationalizing a Buddhist model of suffering (Tyson and Pongruengphant 2007). If it is the case that there is no standard operationalized definition of suffering in clinical psychology, then it is difficult to provide empirical support for the distinction made by Monteiro et al. (2015) that traditional mindfulness aims at "understanding and uprooting the fundamental causes of suffering" while contemporary mindfulness aims for "relief (if not always freedom) from symptoms and attitudes that result in distress" (p. 11).

Based upon a similar concern about the minimal Buddhist content and context of MBIs, new psychotherapies (Loizzo et al. 2009; Miller 2014; Shonin et al. 2014a) have explicitly aimed to draw more from traditional Buddhism. Miller (2014) argued for how a Buddhist-based psychotherapy grounded in what she calls "awakened presence" and "effortless mindfulness" could "heal all forms of mental and emotional suffering" (pp. 19, 185). This model also "aims to move beyond symptom reduction to the liberative recognition of the empty transparency of self and phenomena" (p. xviii). While her theoretical model includes selected patient testimonies, it has not yet been empirically evaluated in a scientific study. Shonin et al. (2014a) provided a qualitative report on a "more traditional Buddhist" intervention called "Meditation Awareness Training," which was subsequently applied in conjunction with CBT in a single-subject case study (Shonin et al. 2014b). As a direct response to the "eclectic" nature of MBIs, Loizzo et al. (2009) developed a 20-week Contemplative Self-Healing program based upon traditional Indo-Tibetan Buddhist principles and applied it in a study on quality of life among cancer survivors (Loizzo et al. 2010). Similar to Loizzo et al. (2009), Shonin et al. (2014a) and Miller (2014), Monteiro et al. (2015) suggested throughout that contemporary mindfulness may be "incomplete" and thus capable of only "symptomatic relief" (pp. 2, 6, 11). By contrast, traditional Buddhism was presented as being more complete and "helps to align one's conduct in accordance with this structure of reality [the Eightfold Path] and attain liberation from suffering" ( $p$. $3)$. Not only has there been no attempt to quantify the degree of suffering that traditional mindfulness and contemporary mindfulness could alleviate, there is presently no means of doing so without consensus on what is meant both by "suffering" and by "liberation" (Davis and Vago 2013). A carefully designed study directly comparing the effects of Meditation Awareness Training or Contemplative Self-Healing to MBSR or MBCT is needed in order to determine whether there is any empirical support for the hypothesis that a greater fidelity to Buddhist principles and practices will be more efficacious in symptom relief or move beyond symptom relief to address the underlying root causes of suffering. Instead, what these criticisms currently amount to is a theoretical and normative claim about traditional and contemporary forms of mindfulness, and one in which the traditional Buddhist framework for suffering and its alleviation has been given the upper hand.

I am less interested in arguing that there is a particular way in which suffering should be understood as I am in exploring the implications of adopting Buddhist views on suffering views that are inextricably linked to Buddhist normative frameworks and soteriological projects. What are the consequences of aiming to develop further an "incomplete" clinical psychology of mindfulness by looking to Buddhist theories about the origin of suffering and practices for attaining "liberation?"

The Pāli term dukkha is commonly translated as "suffering, " but translators (e.g., Anālayo 2003) have pointed out the problems with this rendering and prefer "stress," "unsatisfactoriness," or simply leaving dukkha untranslated. The canonical literature attributes to the Buddha the following definition of dukkha: "Birth is suffering, aging is suffering, illness is suffering, death is suffering; union with what is displeasing is suffering; separation from what is pleasing is suffering; not to get what one wants is suffering; in brief, the five aggregates subject to clinging are suffering" (SN 56.11, Bodhi 2000, p. 1844). Elsewhere, the Buddha explains that there are ultimately three kinds of suffering: "The suffering due to pain, the suffering due to formations, the suffering due to change" (SN 38.14, Bodhi 2000, p. 1299). In the foundational teachings known as the Four Noble Truths (SN 56.11) and elsewhere in the early discourses (AN 6.63, SN 36.5-6), the Buddha's teachings trace the origin of suffering to craving (tanhāa). While pleasant, painful, and neutral feelings will inevitably arise, an instructed disciple of the Buddha's teaching remains "detached" from them, and therefore does not compound physical and emotional pain with additional mental suffering (SN 36.6, Bodhi 2000, p. 1265). Brewer et al. (2013) drew upon Buddhist texts, Buddhist psychological models (Grabovac et al. 2011) and psychological literature on affective bias and addiction in order to operationalize "craving" for application to the treatment of addictive behaviors. This exemplifies the type of translation work that is needed in order to ensure that the relevance of Buddhist theories about concepts such as "craving" and the more ambiguous "suffering" is demonstrated by situating them in relationship to existing psychological literature. However, adopting Buddhist models for the alleviation of suffering that rely too much upon the attenuation of desire and the cultivation of equanimity also promotes a form of ideal affect that is culturally specific. For example, many Asian cultures value low-arousal emotions like calm, whereas Americans prefer high-arousal positive states (Tsai et al. 2007). Differences in ideal affect may prove to be a confound given that mismatch between therapist and patient values and worldviews can have an impact on treatment efficacy (Zane et al. 2005).

Elsewhere in the early canonical literature (e.g., SN 12.23), and throughout the Buddhist tradition (e.g., Tsongkhapa 
2000), the origin of suffering is explained not just in relation to craving but also by recourse to central Buddhist teachings concerning the problem of karma and the overcoming of ignorance. Buddhist models of suffering grounded in karma and ignorance, as well as the normative goal of the complete liberation of suffering through attaining "awakening," may not be compatible with western psychological conceptions of suffering and well-being. McCown (2013) acknowledged this potential problem when he investigated different dimensions of Buddhist ethics for MBIs and concluded that any ethics grounded in karma and rebirth would lead to a clash of worldviews if explicitly adopted by mental healthcare professionals. He chose instead to glean a set of values from the implicit "ethical space" that emerges from the relational aspects of MBIs. I suspect that to those calling for a greater congruency between MBIs and right mindfulness, this approach would seem insufficient, as it neither called for an updated vision of mindfulness nor did it promise a more comprehensive "liberation" from suffering beyond the symptomatic reduction currently offered. Until the specific nuances of Buddhist conceptions of "suffering" and its ending can be operationalized, contemporary mindfulness may have to remain content with empirically measurable outcomes, such as symptomatic relief of stress, depression, anxiety, and addiction. Otherwise, the claim of a greater reduction of suffering is based only in the worldview of traditional Buddhism, without a clear means of intersecting with the empirical research that supports the development of contemporary MBIs.

\section{Universal Mindfulness}

At play in the debates between traditional mindfulness and contemporary mindfulness are questions over the "secular" nature of Buddhism and MBIs. Although there are a few psychologists who have insisted on the secular nature of Buddhism (e.g., Miller 2014), a more common position is that MBIs such as Mindfulness-Based Stress Reduction (MBSR) and Mindfulness-Based Cognitive Therapy (MBCT) are themselves secularized treatments inspired by Buddhist theory and practice, but divorced from the more problematic "religious" elements of Buddhism: its cosmologies, beliefs, and rituals.

In establishing MBSR, Kabat-Zinn (1990, p. 12) emphasized that mindfulness is, in essence, "universal," a description he has echoed elsewhere (Kabat-Zinn 2010, 2011). This means that mindfulness as a particular way of paying attention, although developed within the context of Buddhism, is not dependent on Buddhism; it is non-proprietary. Reflecting upon this in 2011, he clarified that he also saw this universal dimension of mindfulness not strictly in terms of pan-human faculties of attention and awareness; rather, Kabat-Zinn (2011) explains how "mindfulness" was employed as a "place-holder" for "a universal dharma that is co-extensive, if not identical, with the teachings of the Buddha" (p. 290). Similarly, Kabat-Zinn (2010) describes MBSR as "wholly based on the non-dual universal dharma that the Dharma within Buddhism has always pointed to... a basic lawfulness in the universe, and in the nature of what we call "the mind"' (p. xiii). A mindfulness that is "universal" cannot delimited by the Buddhist tradition.

Throughout the literature on contemporary mindfulness, these positions have been echoed in various ways. One version has treated the universal dimensions of mindfulness as nonproprietary, divorceable from Buddhism, and therefore secular. The other approach has emphasized the universal dimensions of mindfulness as indicative of the truth of the Buddha's teachings and has been concerned over deviations from the context of traditional mindfulness. For example, Cullen (2011) claimed, on the one hand, that MBIs are secular; they offer "access to insight and deep levels of mind without religion $[\ldots]$ without having to believe in something on faith alone" ( $p$. 190). While on the other hand, she suggested that the increasing tendency for MBI instructors to engage in long-term retreats at Buddhist institutions "may herald the emergence of MBSR as a lineage [of American Dharma]" (p. 190). As with Kabat-Zinn's claims, there was an assumption that MBIs embody at least a version of the Buddha-Dharma that is nevertheless universal and secular, even if there was at the same time an ongoing desire to see MBIs as faithful to Buddhist principles.

Monteiro et al. (2015) also explored this tension when they suggested, following Gethin (1992/2001), that the Eightfold Path is a "law of nature" to which human beings are "universally subject" (p. 3). Yet at the same time, throughout the article, they expressed their concern about mindfulness being "misappropriated" (p. 2) or "misguided" (p. 12) and also stated that "the usefulness of contemporary, primarily clinical, mindfulness is not as much in question as is its faithfulness to the Buddhist path of practice it claims as its root" (p. 7). A misappropriation or misguided and unfaithful application is, therefore, one that is insufficiently Buddhist - specifically with respect to conceptions of "right mindfulness" and Buddhist ethics.

\section{Consequences of Introducing Right Mindfulness and Buddhist Normative Frameworks into Contemporary Mindfulness}

I am not inclined to attempt to determine conclusively whether mindfulness is inherently ethical in traditional Buddhism, especially given the multitude of conflicting sources that one could possibly draw upon. The debates within traditional Buddhism concerning whether mindfulness (sati) is a universal and ethically neutral faculty of mind or a more narrowly defined mental faculty that is inherently wholesome and ethical have been covered at length elsewhere (Anālayo 2003; 
Bodhi 2011; Dreyfus 2011; Gethin 1992/2001, 2011; Nyanaponika 1998; Olendzki 2011). It is worth mentioning, though, that Monteiro et al. (2015) pointed out the potential limitations of understanding mindfulness as mere "bare attention," a position that has also been called into question from traditional Buddhist perspectives (Bodhi 2011; Olendzki 2011; Thanissaro 2012). This is an important point because they went on to suggest that "reducing mindfulness to attention in the absence of an understanding of ethical action results in the practice becoming wrong mindfulness," which they contrasted with "right mindfulness" (p. 6). A number of early Buddhist discourses also distinguish wrong mindfulness from right mindfulness (Anālayo 2003). In most cases, what is meant by wrong mindfulness is not detailed, but the Sallekha Sutta (MN 8.12) differentiates wrong mindfulness (micchāsatī) from being unmindful (mutthassatī), contrasting the former with right mindfulness (sammāsatī) and the latter with being established in mindfulness (upatthitasatī) (Bodhi 1995, p. 126-127). The fact that there could be a "wrong" mindfulness, and that it is not simply to be unmindful, would seem to suggest that at least in the early Buddhist discourses, "mindfulness" was not inherently ethical and that what made right mindfulness "right" was its fidelity to Buddhist doctrinal, practical, moral, and soteriological concerns.

Buddhist commentators Thanissaro (2012, p. 14-16) and Anālayo (2003, pp. 51-52) have argued that right mindfulness involves mindfulness (sati) joined together with diligence (ātapi) and clear comprehension (sampajāna) and directed towards the purpose of "keeping in mind" the various applications of "right view" and "right effort," which include, among other things, the discrimination of wholesome and unwholesome qualities. Monteiro et al. (2015) also recognized this to an extent when suggesting that right mindfulness entails "discernment between unwholesome and wholesome states of mind" (p. 6). In this sense, their two suggestions that contemporary mindfulness might fall short of "right mindfulness" and that it might be incomplete on account of an absence of a Buddhist ethical framework largely amount to the same thing. That is to say, "right mindfulness," whether traditional or contemporary, is mindfulness oriented within a Buddhist ethical framework. Contemporary mindfulness could therefore also be "wrong mindfulness," but only from the perspective of normative Buddhism.

What I would like to explore is how these observations about the potential shortcomings of contemporary mindfulness could possibly coexist with a commitment to the universality and secularity of MBIs. Again, as above, I am not going to prescribe how ethical contemporary mindfulness should be; rather, I will briefly explore some of the potential consequences if the contemporary mindfulness movement takes seriously the suggestion made by Monteiro et al. (2015) that "terminology and concepts of traditional mindfulness must continue to be a focus of discussion so that there is clarity of intention and confidence in the content that is being taught" (p. 12).

As mentioned above, some clinical interventions have already embraced Buddhist principles and practices more fully in response to the perceived secularity or lack-of-depth in MBIs. However, this approach has also had its consequences. Central to its therapeutic program, the Contemplative Self-Healing program developed by Loizzo et al. (2009) explicitly taught core doctrines of Indo-Tibetan Buddhism as a challenge to "extreme views" associated with scientific materialism on the one hand and Christian theology on the other. This has not gone unnoticed by critics of the explicitly religious or quasi-religious nature of complementary and alternative medicines (Brown 2013). Throughout her monograph on complementary and alternative medicine (CAM) in America, Brown (2013) explored the various strategies that CAM treatments such as acupuncture, yoga, and energy healing have employed to downplay, mask, or camouflage their religious roots or metaphysical worldviews, especially when initially marketing services to potential clients. Specifically commenting on the role of yoga and meditation in schools, Brown (2013) argued that "following Edwards [v. Aguillard (1987)], a stated secular purpose, such as making better students and teachers - a claim commonly made for mindfulness meditation - should not be allowed to mask the purpose or effect of advancing or endorsing religion" (p. 223). Indeed, critics of the Hawn Institute's MindUPTM program have accused it of masking Buddhist beliefs, goals, and values (Wilson 2014). On this point, it is instructive to look at the precedent set by Transcendental Meditation (TM) and its relationship to government-funded institutions such as public schools.

In describing the influence of Transcendental Meditation on the public perception of meditation in the West, McCown et al. (2010) concluded that "the factors at work here - translation into Western language and settings, popular recognition, adoption within scientific research in powerful institutions, and the use of sophisticated marketing public relations techniques - represent a model for success in the building of new social movements" (p. 47). It is not difficult to see how the enthusiasm around contemporary mindfulness is following in the footsteps of TM. However, given that MBIs and MBI research are often government funded, and given the ongoing aspirations to develop mindfulness programs in public schools, adopting increasingly Buddhist rhetoric, values, principles, and practices should be considered carefully. It may not be sufficient simply to claim that mindfulness is secular.

In the court case Malnak v. Yogi (1979), a course on Transcendental Meditation and the "Science of Creative Intelligence," which was taught as an elective in a New Jersey public school, was deemed to have "a primary effect of advancing religion and religious concepts." Importantly, this 
case concerned not just TM but also the ritual used in preparation for the practice of TM as well as the supplementary education program on "creative intelligence" that provided the theoretical underpinning for TM practice. Despite the claims put forth by TM advocates that the ritual was "secular" and that "creative intelligence" was a "science," the court concluded that the course was religious in part because it "provides answers to questions concerning the nature both of world and man $[\ldots]$ and the way to unlimited happiness," that is to say, it addressed matters of "ultimate concern." The case went on to characterize TM by stating that "although it is not as comprehensive as some religions - for example, it does not appear to include a complete or absolute moral code - it is nonetheless sufficiently comprehensive to avoid the suggestion of an isolated theory unconnected with any particular world view or basic belief system."

It is worth pausing to reflect on the call in Monteiro et al. (2015) for contemporary mindfulness to sustain "well-being past the symptomatic relief" (p. 11) and to include "an ethical framework in the form of ethical intentions" (p. 9). Would these directions, as they suggest in regard to the latter, "pose no threat to the social or religious identification that participants may hold" (p.9)? Or, do these claims require a close association with Buddhist ethics and soteriology that would be seen as embodying absolute moral codes or addressing matters of ultimate concern? As mentioned above, Miller (2014) has already outlined an approach to mindfulness-based psychotherapy that similarly purports to move beyond symptom reduction to liberation. She appealed to "awakened presence" as a "fearlessly accurate reception of and interaction with the way things truly are" (p. xviii) and as the "true nature of the mind" that is "the ultimate medicine to heal all forms of mental and emotional suffering" (p. 19). Will the presence, whether implicit or explicit, of additional Buddhist values, practices, and frameworks change the perceived secularity of MBIs?

The requirements for MBI teacher training may also prove to be a confound in advancing an argument for their secularity. According to McCown et al. (2010), MBSR requires a "3-year history of daily meditation practice; participation in two 5-day or longer mindfulness retreats in the Theravada or Zen traditions; three years of body-centered practice, such as Hatha Yoga" (p. 15). The authors further explained that in comparison to other MBIs, MBSR asks for a stronger "existential commitment" to embodying the practice because "the person, the being, of the teacher is what does the teaching" (p. 16). For some like Cullen (2011), as mentioned above, this pointed to MBIs as a new "lineage" of American Buddhism. However, courts ruling on cases involving religious rights and religious freedoms have looked to various metrics, including the Lemon test, the Agostini test, and the endorsement test, in order to evaluate, for instance, "whether the [government] aid has the effect of advancing or inhibiting religion," which could be established if "the aid creates an excessive entanglement between government and religion" (Witte 2005, p. 195). If mindfulness is to be perceived as "secular" and not "excessively entangled" with religion, requiring the therapists of MBIs to engage in long-term practice exclusively at Buddhist centers and to have existential commitments to particular worldviews may not be tenable. As in Malnak v. Yogi, such requirements could even lead to applications of mindfulness in places like public schools being deemed unconstitutional.

\section{Conclusions}

In this commentary, I have suggested that the assumed fit between Buddhist and psychological views on suffering and its alleviation needs to be more critically evaluated and operationalized. The assumed congruence with respect to suffering exemplified by Monteiro et al. (2015) also resulted in the adoption of Buddhist normative frameworks that positioned contemporary mindfulness as being oriented towards mere symptom reduction. It also resulted in a further hypothesis, yet to be empirically substantiated, that greater treatment efficacy if not total liberation from suffering is possible through bringing contemporary mindfulness more in line with Buddhist conceptions of "right mindfulness" and with Buddhist ethics. I have also argued that the confusion over whether contemporary mindfulness is universal in a secular sense or is faithful to its Buddhist origins has resulted in conflicting goals and outcomes. If contemporary mindfulness is secular, it need not be evaluated based upon its fidelity to traditional Buddhist conceptions of ethics, suffering, liberation, or awakening. In fact, if it is to continue to reap the benefits of being perceived as a secular therapy, it needs to incorporate additional elements of Buddhist theory and practice by operationalizing them in such a way that their efficacy towards desired outcomes can be measured and evaluated empirically. In this sense, "right mindfulness" might not be right for contemporary mindfulness, as adopting Buddhist theories of suffering, promises of liberation, standards for training therapists, and moral frameworks may result in MBIs being viewed as advancing or being excessively entangled with religion and thus jeopardize their continued use in medical and educational settings. Certainly, Buddhist theory and practice has much more to offer to clinical psychology, and scientists, scholars, practitioners, and clinicians should continue to work together to operationalize candidate theories about both the nature of suffering and practices for its alleviation in order to determine - through empirical research not a priori assumptionswhether or not contemporary mindfulness could benefit from being brought more in line with the broader context of traditional mindfulness. To do otherwise would be an act of faith. 


\section{References}

Anālayo. (2003). Satipatthāna: the direct path to realization. Cambridge: Windhorse Publications.

Bishop, S. R., Lau, M., Shapiro, S., Carlson, L., Anderson, N. D., Carmody, J., Segal, Z. V., Abbey, S., Speca, M., Velting, D., \& Devin, G. (2004). Mindfulness: a proposed operational definition. Clinical Psychology: Science and Practice, 11(3), 230-241.

Bodhi, B. (1995). The middle length discourses of the Buddha: a translation of the Majjhima Nikāya. Boston: Wisdom.

Bodhi, B. (2000). The connected discourses of the Buddha: a translation of the Samyutta Nikāya. Boston: Wisdom.

Bodhi, B. (2011). What does mindfulness really mean? A canonical perspective. Contemporary Buddhism, 12(1), 19-39.

Brewer, J., Elwafi, H., \& Davis, J. H. (2013). Craving to quit: psychological models and neurobiological mechanisms of mindfulness training as treatment for addictions. Psychology of Addictive Behaviors, 27(2), 366-379. doi:10.1037/ a0028490.

Brown, C. G. (2013). The healing gods: complementary and alternative medicine in Christian America. Oxford: Oxford University Press.

Cullen, M. (2011). Mindfulness-based interventions: an emerging phenomenon. Mindfulness, 2, 186-193.

Davis, J. H., \& Vago, D. R. (2013). Can enlightenment be traced to specific neural correlates, cognition, or behavior? No, and (a qualified) Yes. Frontiers in Psychology, 4(870), 1-4. doi:10.3389/fpsyg. 2013.00870.

Dreyfus, G. (2011). Is mindfulness present-centered and non-judgmental? A discussion of the cognitive dimensions of mindfulness. Contemporary Buddhism, 12(1), 41-54.

Germer, C. K. (2013). Mindfulness: what is it? Does it matter? In C. K. Germer, R. S. Siegel, \& P. R. Fulton (Eds.), Mindfulness and psychotherapy (2nd ed.). New York: The Guilford Press.

Gethin, R. (1992/2001). The Buddhist path to awakening: a study of the Bodhi-Pakkhiyā Dhammā. Oxford: Oneworld.

Gethin, R. (2011). On some definitions of mindfulness. Contemporary Buddhism, 12(1), 263-279.

Goyal, M., Singh, S., Sibinga, E. M. S., Gould, N. F., Seymour, A. R., Sharma, R., Berger, Z., Sleicher, D., Maron, D. D., Shihab, H. M., Ranasinghe, P. D., Linn, S., Saha, S., Bass, E. B., \& Haythornthwaite, J. A. (2014). Meditation programs for psychological stress and well-being: a systematic review and meta-analysis. JAMA Internal Medicine, 174, 357-368. doi:10.1001/ jamainternmed.2013.13018.

Grabovac, A., Lau, M., \& Willett, B. (2011). Mechanisms of mindfulness: a Buddhist psychological model. Mindfulness, 2, 154-166. doi:10.1007/s12671-011-0054-5.

Kabat-Zinn, J. (1990). Full catastrophe living: using the wisdom of your body and mind to face stress, pain, and illness. New York: Random House.

Kabat-Zinn, J. (2010). Forward. In D. McCown, D. Riebel, \& M. S. Micozzi (Eds.), Teaching mindfulness: a practical guide for clinicians and educators. New York: Springer.

Kabat-Zinn, J. (2011). Some reflections on the origins of MBSR, skillful means, and the trouble with maps. Contemporary Buddhism, 12(1), 281-306.

Loizzo, J., Charlson, M., \& Peterson, J. (2009). A program in contemplative self-healing: stress, allostasis, and learning in the Indo-
Tibetan tradition. Annals of the New York Academy of Sciences, $1172,123-147$.

Loizzo, J. J., Peterson, J. C., Charlson, M. E., Wolf, E. J., Altemus, M., Briggs, W. M., Vahdat, L. T., \& Caputo, T. A. (2010). The effect of a contemplative self-healing program on quality of life in women with breast and gynecologic cancers. Alternative Therapies in Health and Medicine, 16(3), 30-37.

Malnak v. Yogi. (1979). 592 F.2d 197 (3rd Cir.).

McCown, D. (2013). The ethical space of mindfulness in clinical practice: an exploratory essay. London: Jessica Kingsley Publishers.

McCown, D., Reibel, D., \& Micozzi, M. S. (2010). Teaching mindfulness: a practical guide for clinicians and educators. New York: Springer.

McMahan, D. L. (2008). The making of Buddhist modernism. Oxford: Oxford University Press.

Miller, R. (2005). Suffering in psychology: the demoralization of psychotherapeutic practice. Journal of Psychotherapy Integration, 15(3), 299-336.

Miller, L. D. (2014). Effortless mindfulness: genuine mental health through awakened presence. New York: Routledge.

Monteiro, L. M., Musten, R. F., \& Compson, J. (2015). Traditional and contemporary mindfulness: finding the middle path in the tangle of concerns. Mindfulness, 6, 1-13. doi:10.1007/s12671-014-0301-7.

Nyanaponika, T. (1998). Abhidhamma studies: Buddhist explorations of consciousness and time. Boston: Wisdom Publications.

Olendzki, A. (2011). The construction of mindfulness. Contemporary Buddhism, 12(1), 71-88.

Shaprio, S. L., Carlson, L. E., Astin, J. A., \& Freeman, B. (2006). Mechanisms of mindfulness. Journal of Clinical Psychology, 62(3), 373-386.

Shonin, E., Van Gordon, W., \& Griffiths, M. D. (2014a). Meditation Awareness Training (MAT) for improved psychological well-being: a qualitative examination of participant experiences. Journal of Religion and Health, 53(3), 849-863. doi:10.1007/s10943-0139679-0.

Shonin, E., Van Gordon, W., \& Griffiths, M. D. (2014b). Cognitive Behavioral Therapy (CBT) and Meditation Awareness Training (MAT) for the treatment of co-occurring schizophrenia and pathological gambling: a case study. International Journal of Mental Health and Addiction, 12, 181-196. doi:10.1007/s11469-013-9460-3.

Thanissaro, B. (2012). Right mindfulness: memory and ardency on the Buddhist path. Valley Center: Metta Forest Monastery.

Tsai, J. L., Miao, F. F., \& Seppala, E. (2007). Good feelings in Christianity and Buddhism: religious differences in ideal affect. Personality and Social Psychology Bulletin, 33, 409-421.

Tsongkhapa. (2000). The great treatise on the stages of the path to enlightenment (Vol. 1). Ithaca: Snow Lion Publications.

Tyson, P. D., \& Pongruengphant, R. (2007). Buddhist and Western perspectives on suffering, stress, and coping. Journal of Religion and Health, 46, 351-357. doi:10.1007/s10943-006-9104-z.

Wilson, J. (2014). Mindful America: the mutual transformation of Buddhist meditation and American culture. Oxford: Oxford University Press.

Witte, J., Jr. (2005). Religion and the American constitutional experiment (2nd ed.). Boulder: Westview Press.

Zane, N., Sue, S., Chang, J., Huang, L., Huang, J., Lowe, S., Srinivasan, S., Chun, K., Kurasaki, K., \& Lee, E. (2005). Beyond ethnic match: effects of client-therapist cognitive match in problem perception, coping orientation, and therapy goals on treatment outcomes. Journal of Community Psychology, 33(5), 569-585. 